\title{
Koefisien Serap Bunyi Papan Partikel Dari Bahan Serbuk Kayu Kelapa
}

\author{
Suhaemi Thamrina*, Seni H.J.Tongkukuta, As'aria
}

aJurusan Fisika, FMIPA, Unsrat, Manado

\section{KA TA KUNCI}

Gelombang

Material Akustik

Koefisien Serap Bunyi

\section{KEYWORDS}

Wave

Material of acoustic

Sound absorption coefficient

AVAILABLE ONLINE

11 February 2013

A B S T R A K
Telah dilakukan penelitian untuk mengetahui karakteristik koefisien
serap bunyi papan partikel dari bahan dasar serbuk kayu kelapa. Papan
partikel dibuat dengan mencampur serbuk kayu kelapa dengan tepung
kanji, dicetak, dan dikeringkan. Sampel berbentuk silinder, dibuat
sebanyak 4 buah dengan tebal : $(1,15 \mathrm{~cm}),(1,95 \mathrm{~cm}),(2,95 \mathrm{~cm})$ dan
(4,05 cm). Nilai koefisien serap bunyi sampel diukur menggunakan alat
ukur koefisien serap bunyi. Hasil penelitian menunjukkan, ketebalan
sampel mempengaruhi nilai koefisien serap bunyi $(\alpha)$ yaitu pada frekuensi
600 Hz. Koefisien serap bunyi ( $\alpha$ semakin menurun dengan
bertambahnya ketebalan papan partikel (sampel penyerap).
A B S T R A C T
The research had been doing to know characteristic sound absorption
coefficient of particle board which made from base material coconut wood
dust. The particle board made by mix of coconut wood dust with
cornstarch then pressed and dried. The particle board as a sample is
cylinder with diameter $8,5 \mathrm{~cm}$. The thick of four samples are $1,15 \mathrm{~cm}$,
$1,95 \mathrm{~cm}, 2,95 \mathrm{~cm}$, and $4,15 \mathrm{~cm}$. The sound absorption coefficient have
measured by sound absorption coefficient instruments. The result is
sample thickness has influence to sound absorption coefficient values
such as at 600 Hz frequencies. Sound absorption coefficients is
decreasing to the increasing of the particle board thickness (absorber
sample).

A B S T R A K serap bunyi papan partikel dari bahan dasar serbuk kayu kelapa. Papan partikel dibuat dengan mencampur serbuk kayu kelapa dengan tepung kanji, dicetak, dan dikeringkan. Sampel berbentuk silinder, dibuat sebanyak 4 buah dengan tebal : $(1,15 \mathrm{~cm}),(1,95 \mathrm{~cm}),(2,95 \mathrm{~cm})$ dan $(4,05 \mathrm{~cm})$. Nilai koefisien serap bunyi sampel diukur menggunakan alat ukur koefisien serap bunyi. Hasil penelitian menunjukkan, ketebalan sampel mempengaruhi nilai koefisien serap bunyi $(\alpha)$ yaitu pada frekuens $600 \mathrm{~Hz}$. Koefisien serap bunyi $(\alpha)$ semakin menurun dengan A B S T R A C T

The research had been doing to know characteristic sound absorption coefficient of particle board which made from base material coconut wood dust. The particle board made by mix of coconut wood dust with cornstarch then pressed and dried. The particle board as a sample is cylinder with diameter $8,5 \mathrm{~cm}$. The thick of four samples are $1,15 \mathrm{~cm}$, $1,95 \mathrm{~cm}, 2,95 \mathrm{~cm}$, and $4,15 \mathrm{~cm}$. The sound absorption coefficient have measured by sound absorption coefficient instruments. The result is sample thickness has influence to sound absorption coefficient values decreasing to the increasing of the particle board thickness (absorber sample).

\begin{abstract}
1. Pendahuluan
Kebisingan adalah suatu masalah yang tengah dihadapi oleh masyarakat Indonesia pada saat sekarang ini, terutama yang tinggal di daerah perkotaan yang sangat ramai oleh berbagai macam aktivitas masyarakat. Hal ini juga disebabkan oleh meningkatnya jumlah kendaraan bermotor yang menghasilkan berbagai polusi yang antara lain adalah kebisingan. Saat ini telah banyak upaya yang dilakukan untuk dapat mereduksi kebisingan pada suatu ruangan yaitu dengan menggunakan bahanbahan peredam dan penyerap suara. Bahan tersebut dalam suatu bangunan biasanya berperan sebagai panel akustik yang dipasang pada dinding pemisah (partisi) dan plafon. Material penyerap bunyi mempunyai peranan penting dalam akustik ruangan, perancangan studio rekaman, ruang perkantoran,
\end{abstract}

sekolah, dan ruang lain untuk mengurangi kebisingan yang umumnya sangat mengganggu. Material ini disebut material akustik yang fungsinya adalah untuk menyerap dan meredam suara. Kebanyakan saat sekarang ini orang banyak menggunakan glasswool dan rockwoll tersebut sebagai peredam bunyi, namun karena harganya yang sangat mahal maka orang berupaya untuk mencari alternatif lain dengan membuat dari bahan yang praktis, murah, dan tersedia melimpah ruah di alam. Bahan tersebut adalah bahan yang mengandung segnoselulosa yang mempunyai daya serap yang baik terhadap bunyi seperti ampas tebu, sekam padi, jerami, dan bahan yang mengandung segnoselulosa lainnya (Metalurgical Physics, 2011).

Rancasa (2003), melakukan penelitian dengan menggunakan bahan dasar serabut kelapa mendapatkan harga koefisien serapan maksimum 
mencapai 0,876. Sampel dengan massa dan ketebalan yang besar mempunyai koefisien serapan maksimum yang lebih besar dibandingkan sampel yang mempunyai massa dan ketebalan yang lebih kecil. Pelapisan sampel dengan karton mempengaruhi kinerja akustiknya yakni menggesernya ke daerah frekuensi yang lebih rendah.

Papan partikel adalah panel-panel kayu yang terbuat dari bahan berlignoselulosa dalam bentuk potongan-potongan kecil atau partikel dari serat yang dicampur dengan perekat sintetis atau bahan pengikat lain yang direkat dengan metode pengempaan (Maloney, 1993).

Material akustik adalah material teknik yang fungsi utamanya adalah untuk menyerap suara/bising. Menurut Lewis dan Douglas (1993) material akustik dapat dibagi ke dalam tiga kategori dasar, yaitu: (1) material penyerap (absorbing material), (2) material penghalang (barrier material), (3) material peredam (damping material). Proporsi energi bunyi yang dipantulkan, diserap, atau diteruskan ditentukan oleh koefisien serap $(\alpha)$. Koefisien serap (absorpsi) adalah angka tanpa satuan yang menunjukkan perbandingan antara energi bunyi yang tidak dipantulkan (diserap) oleh material pembatas berbanding keseluruhan energi bunyi yang mengenai material pembatas. Bidang pembatas yang merupakan penyerap sempurna memiliki nilai koefisien serap 1, sementara yang memantulkan sempurna nilainya mendekati 0 . ( Mediastika, 2009 ).

Kata bunyi mempunyai dua definisi, yaitu: (1) secara fisis, bunyi adalah penyimpangan tekanan, pergeseran partikel dalam medium elastik seperti udara dan (2) secara fisiologis, bunyi adalah sensasi pendengaran yang disebabkan penyimpangan fisis yang digambarkan diatas (Doelle, 1993).

Gelombang bunyi didefinisikan sebagai gelombang mekanik longitudinal berfrekuensi 20 sampai $20.000 \mathrm{~Hz}$ yang menjalar melalui medium elastis dan dapat ditangkap oleh indra dengar manusia (Halliday dan Resnick, 1978).

Apabila suatu gelombang bunyi melewati medium fisik maka intensitas bunyi akan menurun sebanding dengan jarak yang ditempuh terhitung mulai terjadinya sumber bunyi tersebut. Peristiwa ini dikenal sebagai attenuasi. Refraksi, refleksi maupun sketer (hamburan) semuanya akan menambah attenuasi bunyi selama dalam proses perambatan (propagasi). Bunyi mengalami attenuasi sedangkan medium menerima energi akustik sehingga menjadi panas, ini merupakan bentuk attenuasi yang dikenal sebagai penyerapan bunyi (medium penyerap energi bunyi) (Gabriel, 2001).

Karakteristik atenuasi sering digunakan sebagai alat pengukuran bagi landasan teori yang menjelaskan fenomena fisika perihal pengurangan intensitas suatu bunyi. Perubahan amplitudo dari pengurangan suatu gelombang adalah sebagai berikut:
Dengan:

$$
I=I_{0} e^{-\alpha x}
$$

$I$ = Intensitas bunyi setelah melewati suatu medium (dB)

$$
\begin{aligned}
& I_{o}=\text { Intensitas mula-mula }(\mathrm{dB}) \\
& \alpha=\text { Koefisien serap bunyi }
\end{aligned}
$$

\section{Metode}

\subsection{Alat dan bahan}

Alat-alat yang digunakan dalam penelitian ini adalah densifikator, 1 set alat pengukur intensitas bunyi, timbangan, oven, gelas ukur, blender, saringan ukuran 25 mess. Sedangkan bahan-bahan yang digunakan adalah serbuk kayu kelapa, tepung kanji.

\section{Tabel 1 - Perbandingan Campuran Tiap Sampel}

\begin{tabular}{|c|c|c|}
\hline No. & $\begin{array}{c}\text { Serbuk kayu kelapa } \\
\text { (gram) }\end{array}$ & $\begin{array}{c}\text { Tepung kanji } \\
\text { (gram) }\end{array}$ \\
\hline 1. & 25 & 15 \\
\hline 2. & 50 & 30 \\
\hline 3. & 75 & 45 \\
\hline 4. & 100 & 60 \\
\hline
\end{tabular}

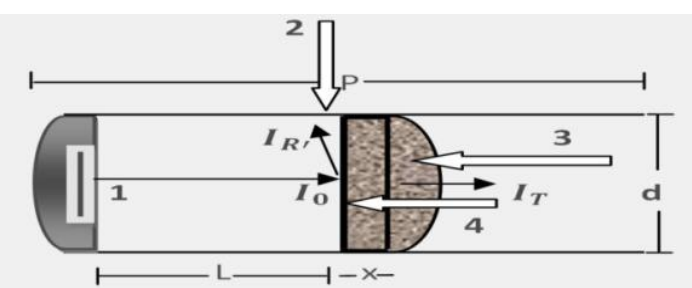

Gambar 1 - Skema pengambilan Gambar. 1) Speaker sebagai sumber bunyi; 2) Posisi Sound level meter dalam pengukuran intensitas yang terukur depan sampel ( $\left.I_{R^{\prime}}\right)$; 3) Posisi Sound level meter dalam pengukuran intensitas yang ditransmisikan $\left.\left(I_{T}\right) ; 4\right)$ Posisi Sound level meter dalam pengukuran intensitas yang datang $\left(I_{0}\right)$ sebelum sampel diletakkan dibagian tengah; 5$) \mathrm{L}=$ jarak sampel ke speaker $=10 \mathrm{~cm}$; 6) $\mathrm{x}=$ tebal sampel $=1,15 \mathrm{~cm}, 1.95$ $\mathrm{cm}, 2,95 \mathrm{~cm}, 4,05 \mathrm{~cm}, 5,35 \mathrm{~cm}, 6,35 \mathrm{~cm}$; 7) d = diameter pipa $=3$ inci $=7,62 \mathrm{~cm} ; 8) \mathrm{P}=$ panjang pipa $=20 \mathrm{~cm}$

\subsection{Pembuatan papan partikel}

Bahan baku serbuk kayu kelapa dalam keadaan kering, diayak untuk mendapatkan ukuran butiran serbuk yang relatif sama. Setelah diayak, serbuk kayu kelapa dan tepung kanji masing - masing ditimbang dengan massa tertentu untuk bahan campuran sampel. Setelah dicampur, dilakukan proses perekatan dengan cara disemprot dengan menggunakan air panas yang sudah ditentukan volumenya lalu diaduk-aduk sampai merata kemudian dicetak menjadi papan partikel dengan tebal $1,15 \mathrm{~cm}$. Setelah menjadi papan partikel, sampel dikeringkan menggunakan oven, kemudian ditimbang massanya. 
Perekatan dan pengeringan dilakukan untuk variasi massa serbuk kayu kelapa yang berbeda seperti pada Tabel 1. Variasi massa serbuk kayu kelapa dan tepung kanji ini dilakukan untuk mendapatkan kerapatan yang sama untuk ketebalan papan partikel yang berbeda-beda.

\subsection{Pengambilan data}

Setelah sampel dikeringkan didalam oven, massa jenis sampel ditimbang terlebih dahulu untuk mendapatkan nilai massa jenis yang seragam dengan menggunakan rumus

$$
\rho=\frac{\operatorname{mass} a(k g)}{\operatorname{volum}\left(\mathrm{m}^{3}\right)}
$$

Papan partikel yang telah dicetak dimasukkan kedalam alat pengukur intensitas bunyi. Letak pengukuran intensitas bunyi dirangkai seperti pada Gambar 1.

\section{Hasil dan Pembahasan}

Pegukuran koefisien serap bunyi dari bahan serbuk kayu kelapa dalam penelitian ini telah dilakukan di Laboratorium Instrumentasi dan Geofisika FMIPA UNSRAT.

Tabel 2 - Koefisien Serap Bunyi, Intensitas Transmisi, Intensitas Refleksi, dan Intensitas Serapan.

\begin{tabular}{|c|c|c|c|c|c|c|}
\hline \multirow{2}{*}{$\begin{array}{c}f \\
(\mathrm{~Hz})\end{array}$} & $\begin{array}{c}\text { Tebal sampel } \\
(\mathrm{cm})\end{array}$ & $\begin{array}{c}\mathrm{I}_{0} \\
(\mathrm{~dB})\end{array}$ & $\begin{array}{c}\mathrm{I}_{T} \\
(\mathrm{~dB})\end{array}$ & $\begin{array}{c}\mathrm{I}_{R} \\
(\mathrm{~dB})\end{array}$ & $\begin{array}{c}\mathrm{I}_{S} \\
(\mathrm{~dB})\end{array}$ & $\begin{array}{c}\alpha \\
\left(\mathrm{cm}^{-1}\right)\end{array}$ \\
\hline \multirow{3}{*}{500} & 1,15 & 66,4 & 63,5 & 0,9 & 2 & 0,03 \\
\cline { 2 - 7 } & 1,95 & 66,4 & 59,23 & 0,6 & 6,57 & 0,5 \\
\cline { 2 - 7 } & 2,95 & 66,4 & 56,53 & 0,1 & 9,77 & 0,05 \\
\cline { 2 - 7 } & 4,05 & 66,4 & 57,56 & 0,9 & 7,74 & 0,03 \\
\hline \multirow{3}{*}{600} & 1,15 & 68,6 & 63,16 & 1,5 & 3,94 & 0,07 \\
\cline { 2 - 7 } & 1,95 & 68,6 & 60 & 1,4 & 7,2 & 0,06 \\
\cline { 2 - 7 } & 2,95 & 68,6 & 58,13 & 1,1 & 9,37 & 0,05 \\
\cline { 2 - 7 } & 4,05 & 68,6 & 56,6 & 1,5 & 10,5 & 0,03 \\
\hline
\end{tabular}

Pengukuran memberikan harga Intensitas bunyi yang diukur masing-masing berupa intensias awal (lo), Intensitas transmisi $\left(I_{T}\right)$, intensitas refleksi $\left(I_{R}\right)$, dan intensitas serapan (Is). Data-data tersebut kemudian memberikan nilai koefisien serap bunyi pada masingmasing sampel seperti pada Tabel 2 dan 3.

Dari Tabel 2 dibuatkan grafik seperti Gambar 2. Dari Gambar 2 terlihat bahwa pada frekuensi $600 \mathrm{~Hz}$ untuk semua sampel mengalami penurunan koefisien serap bunyi. Semakin tebal sampel nilai koefisien justru semakin kecil. Sampel 1 dan 2 adalah merupakan sampel yang mempunyai penyerapan bunyi yang paling bagus bila dibandingkan dengan sampel yang lainnya. Seperti teori yang dikemukakan oleh Mediastika ( 2009 ), bahwa belum tentu semakin tebal sampel, koefisien serap bunyi pun ikut meningkat. Hal ini benar hanya untuk bunyi frekuensi rendah namun tidak selalu untuk frekeunsi tinggi.

Tabel 3 - Koefisien Serap Bunyi terhadap Ketebalan untuk Frekuensi $600 \mathrm{~Hz}$.

\begin{tabular}{|l|c|c|c|c|}
\hline \multirow{2}{*}{$\begin{array}{l}\text { Fre- } \\
\text { kuensi } \\
(\mathrm{Hz})\end{array}$} & \multicolumn{4}{|c|}{ Koefisien serap bunyi pada sampel } \\
\cline { 2 - 5 } & $\begin{array}{c}1,15 \\
\mathrm{~cm}\end{array}$ & $\begin{array}{c}1,95 \\
\mathrm{~cm}\end{array}$ & $\begin{array}{c}2,95 \\
\mathrm{~cm}\end{array}$ & $\begin{array}{c}4,05 \\
\mathrm{~cm}\end{array}$ \\
\hline 600 & 0,07 & 0,06 & 0,05 & 0,04 \\
\hline
\end{tabular}

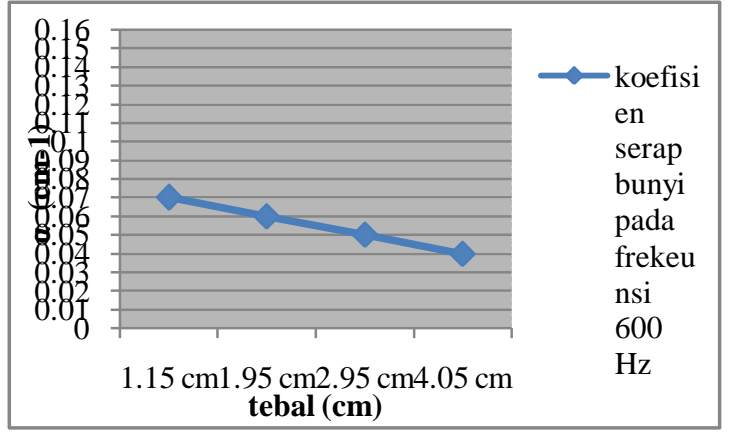

Gambar 2 - Koefisien Serap Bunyi untuk Frekuensi $600 \mathrm{~Hz}$

\section{Kesimpulan}

Dari penelitian yang telah dilakukan, dapat disimpulkan bahwa ketebalan sampel mempengaruhi nilai koefisien serap bunyi $(\alpha)$ yaitu pada frekuensi $600 \mathrm{~Hz}$. Koefisien serap bunyi $(\alpha)$ semakin menurun dengan bertambahnya ketebalan papan partikel (sampel penyerap)

\section{Daftar Pustaka}

Doelle, L.L. 1993. Akustik Lingkungan . Terjemahan Lea Prasetyo. Erlangga, Jakarta

Gabriel, J.F. 2001. Fisika Lingkungan. Hipokrates, Jakarta

Halliday, D dan Robert Resnick. 1996. 
Fisika Jilid I. Terjemahan Pantur Silaban. Erlangga, Jakarta.

Lewis, H.B and Dougals, H.B. 1994. Industrial Noise Control Fundamentals and Aplications, New York

Maloney, T.M. 1993. Modern Particleboard and Dry Process Fiberboard Manufactoring. Miller Freeman Inc, New York

Mediastika, C.E. 2009. Material Akustik Pengendali Kualitas Bunyi Pada Bangunan. ANDI, Jogjakarta.
Metalurgical Physics. 2011. Pengaruh Komposisi Serat Nanas Terhadap Koefisien Penyerapan Bunyi [skripsi]. FMIPA UNP, Padang http://wahyudilhayat.blogspot.com [12 september 2011]

Rancasa, F. 2003. Uji Karakteristik Material Akustik Berbahan Dasar Sabut Kelapa Dengan Metode Tabung Impedansi Dua Mikropon [skripsi]. FMIPA UNS, Surakarta. 